\title{
Retinoic acid receptor signaling levels and antigen dose regulate gut homing receptor expression on CD8 ${ }^{+}$T cells
}

\author{
M Svensson ${ }^{1}$, B Johansson-Lindbom ${ }^{1}$, F Zapata ${ }^{1}$, E Jaensson ${ }^{1}$, LM Austenaa ${ }^{2}$, R Blomhoff ${ }^{2}$ and \\ WW Agace ${ }^{1}$
}

Recent studies have highlighted a central role for intestinal dendritic cells (DCs) and vitamin A metabolite retinoic acid (RA) in the generation of $\alpha 4 \beta 7$ + CCR9+ "gut tropic" effector T cells. Here, using RA-responsive element reporter mice, we demonstrate that both splenic and mesenteric lymph node (MLN) DCs enhanced retinoic acid receptor (RAR) signaling in CD8 ${ }^{+}$T cells; however, only a subset of MLN DCs, expressing the integrin $\alpha$-chain CD103, induced an early RAR signal that is required for efficient CCR9 induction. MLN-primed CD8 ${ }^{+} \mathrm{T}$ cells also received enhanced RAR-dependent signals compared with splenic-primed $\mathrm{CD} 8^{+} \mathrm{T}$ cells in vivo. Further DC-mediated induction of gut homing receptors was inhibited at a high antigen dose without influencing RAR signaling events, and resulted in less efficient CD8 ${ }^{+} \mathrm{T}_{\text {-cell }}$ entry into the small intestinal mucosa. These results highlight a complex interplay between antigen dose and DC subsetinduced RAR signaling events in the generation of tissue tropic effector T-cell subsets.

\section{INTRODUCTION}

Effector T-cell migration into lymphoid and non-lymphoid tissues is a multistep process mediated by the coordinated interaction of adhesion receptors on the T-cell surface with their ligands on vascular endothelial cells. Two homing receptors, the integrin $\alpha 4 \beta 7$ and the CC chemokine receptor (CCR) 9 , have been a particular focus of attention in regulating effector T-cell migration to the intestinal mucosa. $\alpha 4 \beta 7$ is expressed at high levels on a subset of circulating antigen-experienced $\mathrm{T}$ cells and mediates their entry into the intestinal mucosa via interactions with mucosal addressin cell adhesion molecule-1, expressed on intestinal lamina propria (LP) microvascular endothelium. ${ }^{1}$ CCR9 is expressed by a subset of $\beta 7^{+} \mathrm{T}$ cells in the circulation and the majority of small intestinal $\mathrm{T}$ cells, but only by a minor fraction of colonic T cells, ${ }^{2-4}$ whereas its ligand CCL25 is constitutively and selectively expressed by small intestinal epithelial cells. ${ }^{2,5}$ T-cell receptor (TCR) adoptive transfer models using neutralizing antibodies to CCL25, or CCR9 $9^{-1-} \mathrm{T}$ cells, have demonstrated a central role for CCL25/CCR9 in effector T-cell migration to the small intestinal mucosa, but not to other peripheral tissues. ${ }^{3,6,7}$ Thus, expression of CCR9 and $\alpha 4 \beta 7$ marks a subset of circulating effector $\mathrm{T}$ cells with enhanced intestinal homing capacity.

Recent studies have highlighted a central role for intestinal lymph nodes and intestinal dendritic cells (DCs) in the generation of CCR9 ${ }^{+} \alpha 4 \beta 7^{+}$effector T cells. ${ }^{6,8-10}$ Using TCR transgenic adoptive transfer models, we and others have demonstrated that $\mathrm{CD} 4^{+}$and $\mathrm{CD} 8{ }^{+} \mathrm{T}$ cells activated in mesenteric lymph nodes (MLNs), but not peripheral lymph nodes or the spleen, are induced to express CCR9 and $\alpha 4 \beta 7.3,6,7,11$ Furthermore, T cells primed with antigen-pulsed MLN or Peyer's patch (PP) DCs, but not splenic or peripheral lymph node DCs or MLN preparations depleted of DCs, expressed CCR9 and high levels of $\alpha 4 \beta 7.6,9,10$

The vitamin A (retinol) metabolite retinoic acid (RA) induces expression of both CCR 9 and $\alpha 4 \beta 7$ on anti-CD 3 and anti-CD28 antibody-activated $\mathrm{CD} 4{ }^{+} \mathrm{T}$ cells and on $\mathrm{B}$ cells. ${ }^{12,13}$ Conversion of retinol into RA is a two-step enzymatic oxidation catalyzed by alcohol and retinal dehydrogenases. ${ }^{14,15}$ Importantly, MLN and PP DCs, but not splenic DCs, were found to be capable of converting ${ }^{3} \mathrm{H}$-all-trans(at)-retinol to ${ }^{3} \mathrm{H}$-at-RA, and the ability of MLN and PP DCs to induce $\alpha 4 \beta 7$ was partially inhibited

${ }^{1}$ Section for Immunology, Lund University, Lund, Sweden. ${ }^{2}$ Faculty of Medicine, Institute of Basic Medical Sciences, University of Oslo, Oslo, Norway. Correspondence: WW Agace (william.agace@med.lu.se) 
with the retinal dehydrogenase inhibitor citral. ${ }^{12}$ RA signals through heterodimeric retinoic acid receptor (RAR)/retinoid $\mathrm{X}$ receptor, ${ }^{16}$ which function as ligand-induced transcription factors by interacting with retinoic acid-responsive elements (RAREs), so-called DR5 sequences, located in the promoter region of target genes to regulate transcription. ${ }^{17,18}$ Addition of a pan-RAR, but not RVR antagonist partially blocked $\alpha 4 \beta 7$ expression on $\mathrm{CD}^{+}{ }^{+} \mathrm{T}$ and $\mathrm{B}$ cells cultured with PP or MLN DCs, ${ }^{12,13}$ and together, these results have led to the suggestion that the selective ability of intestinal DCs to induce gut homing receptors on responding lymphocytes in vitro lies in their ability to generate RA and induce RAR signaling in these cells. Nevertheless, we have recently identified a subset of DCs within the murine MLN that express the integrin $\alpha \mathrm{E}(\mathrm{CD} 103) \beta 7$. These cells make up approximately $40 \%$ of DCs within the MLN, and T cells primed with antigen-pulsed $\mathrm{CD}_{103}{ }^{+}$, but not $\mathrm{CD}_{103}{ }^{-}$, MLN DCs expressed CCR9 and high levels of $\alpha 4 \beta 7 .{ }^{8}$ Thus, not all MLN DCs are efficient at generating gut homing effector T cells. ${ }^{8}$ Moreover, splenic and CD $103^{-}$MLN DCs are capable of inducing moderate levels of $\alpha 4 \beta 7$ on responding T cells in vitro, particularly after long-term cultures. ${ }^{8,19}$

TCR signal strength during T-cell activation, defined for example by antigen dose or the duration of the antigen-presenting cell (APC)/T-cell interaction, ${ }^{20}$ plays a critical role in determining the outcome of effector T-cell differentiation. For $\mathrm{CD}^{+} \mathrm{T}$ cells, antigen dose has been demonstrated to regulate cytolytic function and interferon- $\gamma$ production, ${ }^{21}$ and brief compared to sustained TCR signaling resulted in reduced expression of the antiapoptotic factor Bcl- $\mathrm{x}_{\mathrm{L}}$ and the interleukin (IL)-2R $\alpha$, IL-15R $\alpha$, and common $\gamma$-chain $(\gamma c)$ cytokine receptors. ${ }^{22}$ The role of antigen dose in the generation of tissue tropic effector $\mathrm{CD}^{+}$T-cell subsets remains to be investigated.

In this study, we have determined the role of DC-induced RAR signaling and antigen dose in regulating gut homing receptor expression on $\mathrm{CD}^{+} \mathrm{T}$ cells. Our results highlight a complex interplay between DC subset-specific, early RAR signaling events and RAR-independent inhibitory signals induced at high antigen dose in the regulation of gut homing receptor expression on $\mathrm{CD}^{+}$effector $\mathrm{T}$ cells.

\section{RESULTS}

\section{DC-mediated induction of gut homing receptors is dependent on RAR signaling}

In initial experiments, we determined whether the ability of MLN DCs to induce CCR9 on responding CD8 ${ }^{+} \mathrm{T}$ cells was in part due to the generation of soluble mediators. TCR-transgenic ovalbumin (OVA)-specific CD8 ${ }^{+} \mathrm{T}$ cells (OT-I cells) were cultured with OVA peptide (pOVA)-pulsed splenic DCs in the lower chamber of a transwell system, in the presence or absence of pOVA-pulsed MLN DCs with or without OT-I cells in the upper insert chambers (Figure 1a). As expected, pOVA-pulsed MLN DCs efficiently induced CCR9 on responding OT-I cells, although pOVA-pulsed splenic DCs did not (Figure 1a, I and II). When MLN DCs were placed in the upper insert, a small percentage of OT-I cells responding to antigen-pulsed splenic DCs expressed CCR9 (Figure 1a, III), and expression was further enhanced by addition of pOVA-pulsed MLN DCs with OT-I cells in the upper insert (Figure 1a, IV). Thus, CCR9 is induced by soluble factor(s) produced by MLN DCs, and the production of this factor(s) is enhanced in the presence of antigenprimed $\mathrm{T}$ cells.

To determine whether MLN DC-mediated induction of CCR9 and $\alpha 4 \beta 7$ on $\mathrm{CD}^{+} \mathrm{T}$ cells was dependent on RAR signaling, pOVA-pulsed MLN DCs were cultured with OT-I cells in the presence of the pan-RAR antagonist AGN194310. ${ }^{23}$ Although AGN194310 had no or minor effects on OT-I cell proliferation, CXC chemokine receptor $3\left(\alpha \mathrm{CR}_{3}\right)$ induction, and CD62L downregulation over a wide range of inhibitor concentrations (Figure 1c, data not shown), it dose-dependently inhibited expression of CCR9 and $\alpha 4 \beta 7$ on responding OT-I cells (Figure 1b,c). Thus, MLN DC-induced RAR signaling is critical for induction of gut homing receptors on $\mathrm{CD}^{+} \mathrm{T}$ cells, as previously shown for CD4 ${ }^{+}$T cells. $^{12}$

To determine whether splenic DC-mediated induction of a4 $\beta 7$ was also dependent on RAR signaling, splenic DCs were pulsed with low-dose pOVA (conditions that enhance induction of this integrin; see below) and incubated with OT-I cells in the presence of AGN194310. Splenic DC-mediated induction of $\alpha 4 \beta 7$ on responding OT-I cells was also completely blocked with $1 \mathrm{nM}$ AGN194310 (Figure 1d). Together, these results suggest that splenic DCs are capable of generating RAR ligands, and that differences in the ability of MLN and splenic DCs to induce CCR9 and $\alpha 4 \beta 7$ on CD8 ${ }^{+} \mathrm{T}$ cells in vitro may lie in the levels of RAR ligands produced, in the kinetics of RAR ligand generation, and/or in the production of additional factors by either DC subset.

\section{RAR signaling in T cells in response to MLN and splenic DCs}

Several retinol metabolites can interact with RAR/RXR to mediate binding to RAREs, including at-RA, 9-cis-RA, and 4-oxo at-RA. ${ }^{23-25}$ Nevertheless, we were unable to detect these metabolites in DC: T-cell co-culture supernatants using sensitive high performance liquid chromatography-atmospheric pressure chemical ionization-mass spectrometry (HPLCAPCI-MS/MS) ${ }^{26}$ (detection limit $0.7 \mathrm{nM}$ ), whereas RA was readily detected in spiked control supernatants (data not shown). Thus, to compare the ability of DCs to induce RAR signaling in T cells, we isolated CD8 ${ }^{+} \mathrm{T}$ cells from DR5 transgenic mice. These mice contain a transgene with three RARE DR5 repeats coupled to a minimal TATA box from the herpes simplex virus thymidine kinase promoter and a luciferase reporter (DR5-luciferase mice; K. Ebihara and R. Blomhoff, unpublished data). Addition of RA dose-dependently enhanced luciferase activity in anti-CD3 antibody-stimulated CD8 ${ }^{+}$DR5-luciferase (DR5.CD8) T cells (Supplementary Figure S1 online), demonstrating that the DR5 transgene is functionally responsive to RAR signals in these cells. As expected, addition of MLN DCs to anti-CD3 antibody-stimulated DR5.CD8 cells induced expression of CCR9 on a subset of responding DR5.CD8 cells, whereas addition of splenic DCs did not, and MLN DC-induced CCR9 expression was inhibited by addition of AGN194310 (Figure 2a). After $24 \mathrm{~h}$ culture, anti-CD3 antibody-stimulated 


\begin{tabular}{|ll|}
\hline 会 MLN DC & OOT-I \\
SPL DC & $\circ$ OT-I (analyzed) \\
\hline
\end{tabular}
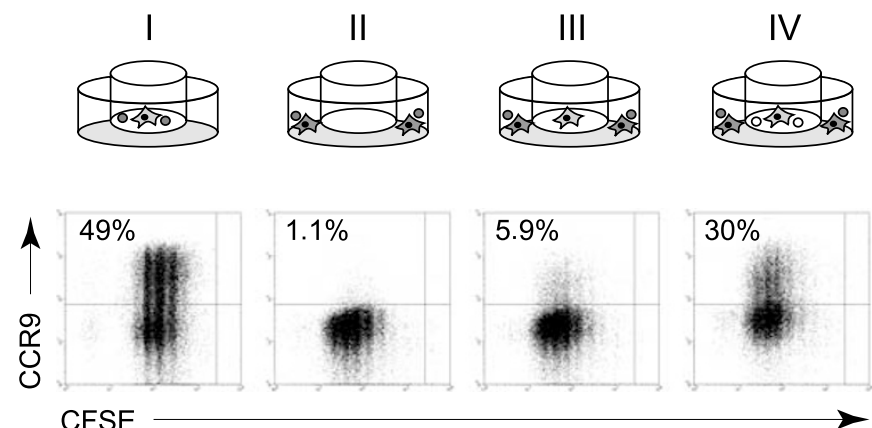

CFSE

c

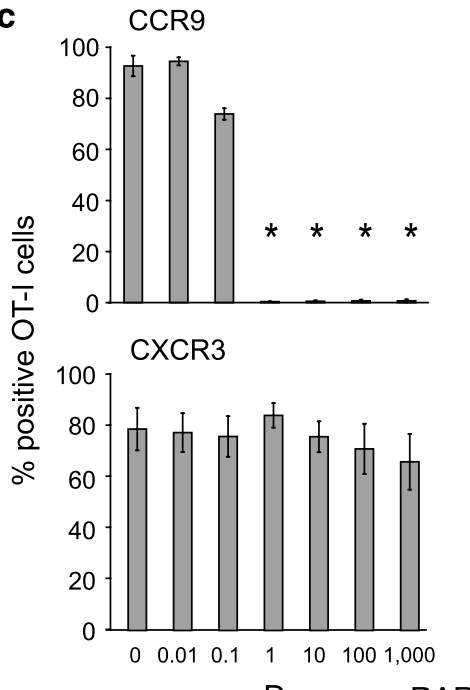

b
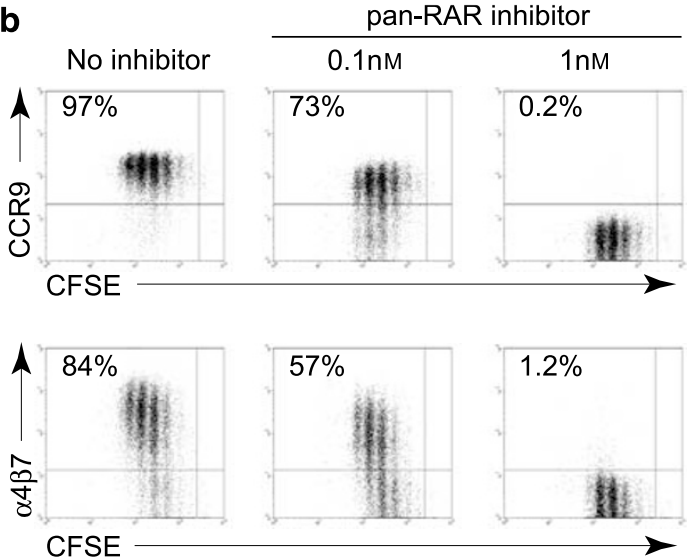

d
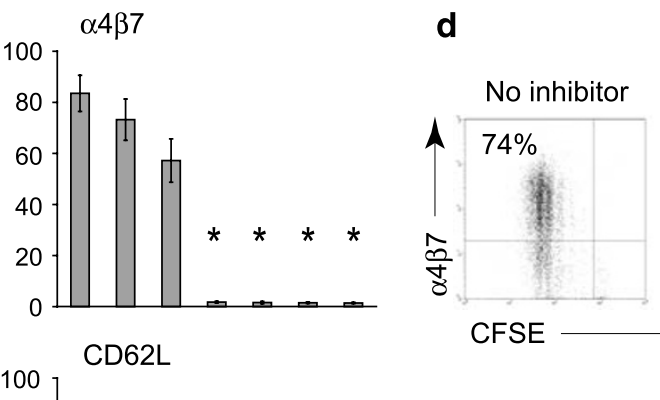

CFSE

Dose pan-RAR inhibitor (nM)

Figure 1 CCR9 and $\alpha 4 \beta 7$ induction requires signaling via RA receptors. (a) Experimental setup to investigate the nature of CCR9-inducing signals. (II-IV) Purified CD $11 \mathrm{c}^{+}$splenic DCs $\left(2.5 \times 10^{5}\right)$ were pulsed with pOVA $(1 \mathrm{nM})$ and incubated with $5 \times 10^{5} \mathrm{CFSE}$-labeled OT-I cells in the lower chamber of a $0.4 \mu \mathrm{m}$ transwell. (I, III, and IV) Purified CD11 $\mathrm{c}^{+}$MLN DCs $\left(10^{5}\right)$ were pulsed with $1 \mathrm{nM}$ pOVA and added (III) alone or (I and IV) together with $2 \times 10^{5}$ CFSE-labeled OT-I cells to the upper insert. After 4 days of culture, OT-I cells cultured with (I) MLN DCs or (II-IV) splenic DCs were analyzed for CCR9 expression by flow cytometry. Results are from one representative experiment of three performed. (b and $\mathbf{c}$ ) RAR signaling is required for induction of CCR9 and $\alpha 4 \beta 7$ expression on OT-I cells. Antigen-loaded $(20 \mathrm{pM}) \mathrm{MLN}$ DCs $\left(10^{5}\right)$ were co-cultured with OT-I cells $\left(2 \times 10^{5}\right)$ in the presence or absence of pan-RAR inhibitor AGN194310. Following 4 days of culture, CCR9 and $\alpha 4 \beta 7$ expression was determined on the OT-I cells by flow cytometry. (c) Bars represent mean \pm s.e.m. from three to four experiments. ${ }^{\star} P<0.05$ compared to no added inhibitor. (d) RAR signaling is required for splenic DC-mediated induction of $\alpha 4 \beta 7$ expression on OT-I cells. Antigen-loaded $(20 \mathrm{pM})$ splenic DCs $\left(10^{5}\right)$ were co-cultured with OT-I cells $\left(2 \times 10^{5}\right)$ in the presence or absence of pan-RAR inhibitor AGN194310. Following 4 days of culture, $\alpha 4 \beta 7$ expression was determined on the OT-I cells by flow cytometry. One representative experiment of four performed. CCR, CC chemokine receptor; CXCR, CXC chemokine receptor; DC, dendritic cell; MLN, mesenteric lymph node; pOVA, ovalbumin peptide; RA, retinoic acid; RAR, retinoic acid receptor; SPL, splenic.

DR5.CD8 cells exhibited enhanced luciferase activity when cultured in the presence of MLN DCs compared with splenic DCs or anti-CD3 antibody stimulation alone, and this enhanced activity was blocked by addition of AGN194310 (Figure 2b). Similar results were obtained when luciferase levels were normalized to the total protein levels (Supplementary Figure S2 online). The levels of MLN DC-induced RAR signaling were similar to those observed after addition of approximately $0.5 \mathrm{nM}$ RA to anti-CD3 antibody-stimulated DR5.CD8 cells (data not shown), consistent with our inability to detect RAR ligands in supernatants by HPLC-APCI-MS/MS. By $72 \mathrm{~h}$, total luciferase activity had increased in all cultures (Figure 2b), even when normalized to total protein content (Supplementary Figure S2 online), indicating enhanced RAR signaling and/or enhanced luciferase accumulation in the cells. Furthermore, at this time point, splenic and MLN DCs induced similar levels of luciferase activity in anti-CD3 antibody-stimulated DR5.CD8 cells (Figure 2b).

The inability of splenic DCs to induce CCR9, despite inducing similar levels of RAR signaling as MLN DCs at late time points, suggested that early RAR signals may be important for induction of CCR9 on responding T cells in these cultures. To test this hypothesis, RA was added to anti-CD3 antibody-primed CD8 ${ }^{+}$ T cells at $0,24,48$, and $72 \mathrm{~h}$, and the expression of CCR9 on 
a

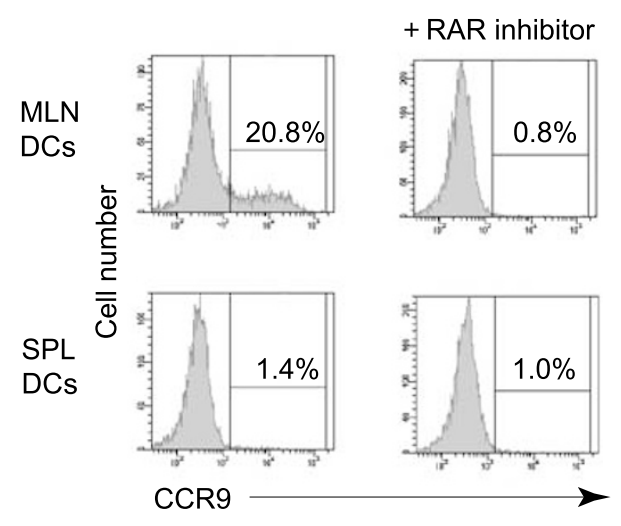

b

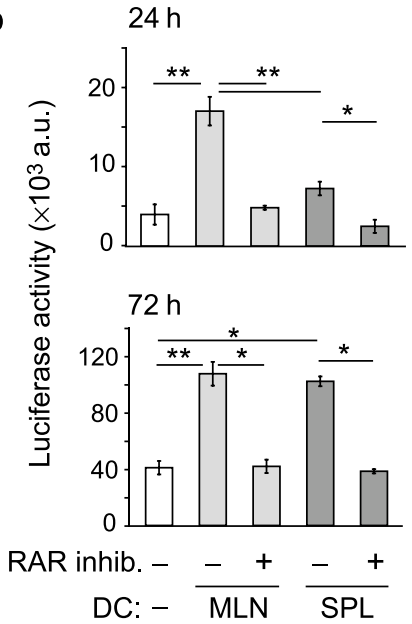

C

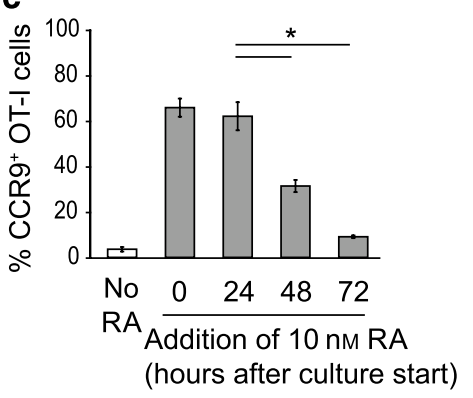

e

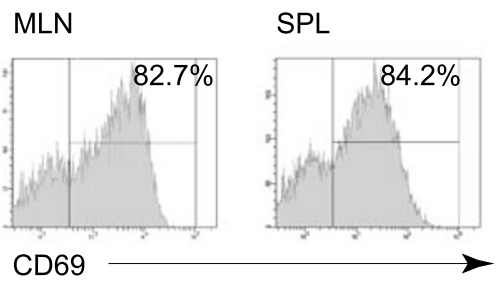

d

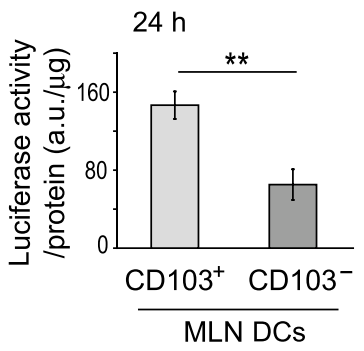

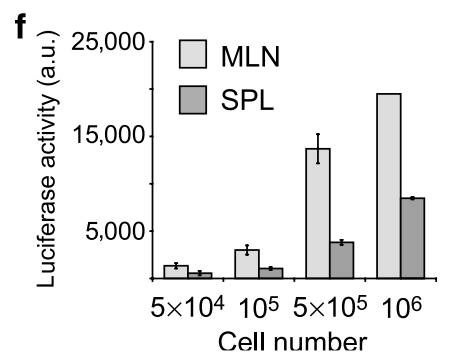

Figure $2 \mathrm{CD}_{103^{+}} \mathrm{MLN}$ but not CD103- MLN or splenic DCs provide early RAR-stimulating signals required for efficient CCR9 induction. (a) CCR9 expression by CD8 ${ }^{+} \mathrm{T}$ cells stimulated with anti-CD3 antibody in the presence of MLN or splenic DCs. A total of $2 \times 10^{5}$ DR5.CD8 cells were stimulated with anti-CD3 antibody $\left(10 \mu \mathrm{g} \mathrm{ml}^{-1}\right)$ in the presence of $10^{5} \mathrm{MLN}$ or splenic DCs, with or without the pan-RAR inhibitor AGN194310 (100 nM). Expression of CCR9 was determined by flow cytometry after $96 \mathrm{~h}$. Numbers represent percentage of CCR9+ CD8 ${ }^{+} \mathrm{T}$ cells. (b) Luciferase activity of DR5.CD8 cells stimulated with anti-CD3 antibody in the presence or absence of MLN or splenic DCs. DR5.CD8 cells were cultured as in a. Luciferase activity was measured after $24 \mathrm{~h}$ (upper panel) or $72 \mathrm{~h}$ (lower panel). Bars represent mean \pm s.e.m. from four to six culture wells from two to three experiments. ${ }^{*} P<0.05,{ }^{\star \star} P<0.01$. (c) Early RAR signaling is required for efficient CCR9 induction in responding T cells. CD $8{ }^{+} \mathrm{T}$ cells were stimulated with anti-CD3 antibody $\left(10 \mu \mathrm{g} \mathrm{ml}^{-1}\right)$. RA $(10 \mathrm{nM})$ was added at indicated time points, and T-cell expression of CCR9 determined after $96 \mathrm{~h}$ of culture. Bars represent mean \pm S.e.m. of the percentages CCR9 ${ }^{+}$OT-I cells from four individual wells from two experiments. ${ }^{\star} P<0.05$. (d) Luciferase activity of anti-CD3 antibody $\left(10 \mu \mathrm{g} \mathrm{ml}^{-1}\right)$-stimulated DR5.CD8 cells cultured in the presence of $10^{5} \mathrm{CD}_{103^{+}}$or $\mathrm{CD} 103^{-} \mathrm{MLN}$ DCs isolated from Flt3L-treated mice. Luciferase activity was measured after 24 and $72 \mathrm{~h}$ and was normalized to the protein content of each individual well. Bars represent mean \pm S. e.m. from five to eight wells from two experiments. ${ }^{\star \star} P<0.01$. (e and f) Luciferase activity of in vivo-activated CD8 ${ }^{+} \mathrm{T}$ cells. DR5.OT-I mice were injected with OVA $(200 \mu \mathrm{g}, \mathrm{IP})$. Forty-two hours later, CD8 ${ }^{+} \mathrm{T}$ cells were purified from the spleen and MLN by MACS and analyzed for (e) CD69 expression by flow cytometry and (f) luciferase activity. (e) Numbers represent percentage of positive cells. (f) Bars represent mean \pm s.d. of three wells. CCR, CC chemokine receptor; DC, dendritic cell; IP, intraperitoneally; MACS, magnetic cell sorting; MLN, mesenteric lymph node; OVA, ovalbumin; RA, retinoic acid; RAR, retinoic acid receptor; SPL, splenic.

responding T cells determined at $96 \mathrm{~h}$. Consistent with an early role for RAR signaling in CCR9 induction by MLN DCs, CD8 ${ }^{+}$ T cells supplemented with $10 \mathrm{nM}$ RA at 0 and $24 \mathrm{~h}$ effectively induced CCR9, whereas inclusion of RA at later time points induced only low levels of CCR9 expression (Figure 2c).

\section{CD103+ MLN DCs have a unique capacity to induce early RAR signaling in CD8 ${ }^{+} \mathrm{T}$ cells}

To determine whether $\mathrm{CD}_{103^{+}}$and $\mathrm{CD} 103^{-}$MLN DCs differed in their capacity to induce RAR signaling in responding $\mathrm{T}$ cells, MLN DCs were isolated from FMS-like tyrosine kinase-3 
ligand (Flt3L)-treated mice, and FACS (fluorescence-activated cell sorter)-sorted $\mathrm{CD}_{103}{ }^{+}$and $\mathrm{CD} 103^{-}$MLN DCs were added to anti-CD3 antibody-stimulated DR5.CD8 cells (Figure 2d). We have previously demonstrated that $\mathrm{CD} 103^{+}$, but not $\mathrm{CD} 103^{-}$, MLN DCs from FLT3 treated mice efficiently induce gut homing receptor expression on $\mathrm{CD}^{+}{ }^{+} \mathrm{T}$ cells, as with untreated mice. ${ }^{8}$ Moreover, although Flt3L treatment resulted in increased numbers of MLN DCs, it had no marked effect on MLN DC subset composition based on expression of $\mathrm{CD} 8 \alpha, \mathrm{CD} 11 \mathrm{~b}, \mathrm{CD} 103$, CCR7, CD40, and CD86 (data not shown). CD103+ MLN DCs induced a significantly higher luciferase activity in responding DR5.CD8 cells compared with CD103- MLN DCs at $24 \mathrm{~h}$, and a similar trend (although not significant) was observed at $72 \mathrm{~h}$. Together, these results suggest that the unique ability of $\mathrm{CD}_{103^{+}}$ MLN DCs to induce CCR9 is due, at least in part, to their ability to induce early RAR signals in responding $\mathrm{T}$ cells.

To determine whether RAR signaling occurs in $\mathrm{CD} 8^{+} \mathrm{T}$ cells following their activation in vivo and whether RAR signaling differs in $\mathrm{CD} 8^{+} \mathrm{T}$ cells primed in the MLN vs. spleen, DR5-luciferase mice were crossed with OT-I mice and DR5.OT-I mice were immunized intraperitoneally (IP) with OVA $(0.2 \mathrm{mg})$. Forty-two hours later, $\mathrm{CD} 8{ }^{+} \mathrm{T}$ cells were purified from the MLN and spleen by magnetic cell sorting (MACS), and luciferase activity was assessed. Although $\mathrm{CD} 8{ }^{+} \mathrm{T}$ cells activated in the MLN and spleen displayed a similar degree of activation, as assessed by CD69 expression (Figure 2e), MLN-primed CD8 ${ }^{+} \mathrm{T}$ cells displayed enhanced luciferase activity on a per cell basis compared with splenic DC-primed CD8 ${ }^{+} \mathrm{T}$ cells (Figure 2f). Thus, $\mathrm{CD}^{+} \mathrm{T}$ cells receive RAR-dependent signals after priming in both the spleen and MLN in vivo; however, the level of RAR signaling is greater in the MLN.

\section{Induction of CCR9 and $\alpha 4 \beta 7$ on CD8 ${ }^{+} T$ cells is antigen dose dependent}

Antigen dose plays a central role in regulating various aspects of T-cell differentiation, including cytokine production and cytolytic function; ${ }^{21}$ however, the role of antigen dose in the induction of tissue homing receptors has yet to be explored. To determine the effect of peptide dose in the induction of gut homing receptors, DCs were pulsed with various doses of pOVA, washed, and their ability to induce gut homing receptors on responding OT-I cells was determined (Figure 3). As peptide dose increased, there was a dramatic reduction in the ability of MLN DCs to induce CCR9 and, although less pronounced, $\alpha 4 \beta 7$, on responding OT-I cells (Figure 3a,b). $\alpha 4 \beta 7$ induction on splenic DC-primed OT-I cells also decreased with increasing peptide dose (Figure 3b). Splenic DCs displayed only a limited capacity to induce CCR9 expression (Figure 3a,b). Differences in CCR9 and $\alpha 4 \beta 7$ expression on OT-I cells responding to the different peptide doses were also observed when comparing cells that had undergone a similar number of divisions (Figure 3c) and thus was cell cycle independent. In contrast to CCR9 and $\alpha 4 \beta 7$, induction of $\mathrm{CXCR}_{3}$ and downregulation of CD62L were similar on MLN and splenic DC-primed T cells and displayed only marginal changes with different peptide doses (Supplementary Figure $\mathbf{3}$ online).

As with total MLN DCs, CD $103^{+}$MLN DCs more efficiently induced CCR9 expression when pulsed with low compared to high antigen doses (Figure 3d), although induction of CCR9 occurred relatively more efficiently at the high antigen dose compared to total MLN DCs. Furthermore, CD103- MLN DCs pulsed with low-dose antigen were capable of inducing some CCR9 on responding OT-I cells, albeit to a much lesser extent than $\mathrm{CD}_{103}{ }^{+}$MLN DCs (Figure 3d). Strikingly, and in marked contrast to gut homing receptors, expression of E-selectin ligand, a molecule involved in effector T-cell localization to inflammatory sites outside the intestine, was induced on OT-I cells by $\mathrm{CD}_{103^{-}}$, and to a lesser extent by $\mathrm{CD}_{103}{ }^{+}$, MLN DCs pulsed with a high antigen dose (Figure 3d).

\section{RAR signaling is not reduced at high antigen dose}

To determine whether increasing antigen dose inhibited the ability of RAR ligands to induce gut homing receptors, OT-I cells were incubated with pOVA-pulsed splenic DCs in the presence of RA. Addition of RA to splenic DC:OT-I cell cultures dosedependently induced expression of CCR 9 and $\alpha 4 \beta 7$ on OT-I cells (compare upper and lower panels in Figure 4a). However, when splenic DCs were pulsed with increasing doses of pOVA prior to co-culture with OT-I cells, the capacity of exogenous RA to induce expression of CCR 9 and $\alpha 4 \beta 7$ decreased (Figure 4a, data not shown). To determine whether the effect of antigen dose was due to an inhibition of RAR signaling, DR5.OT-I cells were activated in vitro with pOVA-pulsed MLN DCs. As with wild-type OT-I cells, CCR9 levels decreased on DR5.OT-I cells when they were stimulated with high-dose pOVA-pulsed MLN DCs (data not shown). Nevertheless, DR5.OT-I cells primed with high-dose pOVA-pulsed MLN DCs showed similar luciferase activity compared with DR5.OT-I cells primed with low-dose pOVA-pulsed MLN DCs (Figure 4b). Together, these results suggest that a negative signal is generated in DC:T-cell co-cultures at higher antigen doses that can inhibit RA-induced expression of CCR9 and $\alpha 4 \beta 7$ downstream of RAR signaling.

\section{CCR9 induction in vivo is antigen dose dependent}

To determine whether CCR9 induction on $\mathrm{CD} 8^{+} \mathrm{T}$ cells is antigen dose dependent in vivo, 5,6-carboxyflurescene succinimidyl ester (CFSE)-labeled CD45.2 ${ }^{+}$OT-I cells were adoptively transferred into CD $45.1^{+}$wild-type recipient mice. Recipients were immunized IP with OVA in the presence or absence of lipopolysaccharide, and CCR9 expression on responding OT-I cells in the MLN was determined 2-3 days later. As the amount of OVA administered was increased, there was a marked and dose-dependent reduction in the proportion of responding OT-I cells that expressed CCR9 (Figure 5a,b), and this reduction was cell cycle independent (Figure 5c). Similar dose-dependent reduction of CCR9 expression was observed when lipopolysaccharide was used as an adjuvant (data not shown). Thus, induction of CCR9 during CD8 ${ }^{+}$T-cell priming in MLN in vivo may also be regulated by antigen dose.

\section{OT-I cell primed with high antigen dose-pulsed MLN DCs home less efficiently to the small intestinal epithelium}

Finally, to determine whether antigen dose has an impact on the ability of OT-I cells to localize to the small intestine, OT-I cells primed in vitro with low $\left(\mathrm{CD} 45.1^{+} \mathrm{CD} 45.2^{+}\right)$and 
a

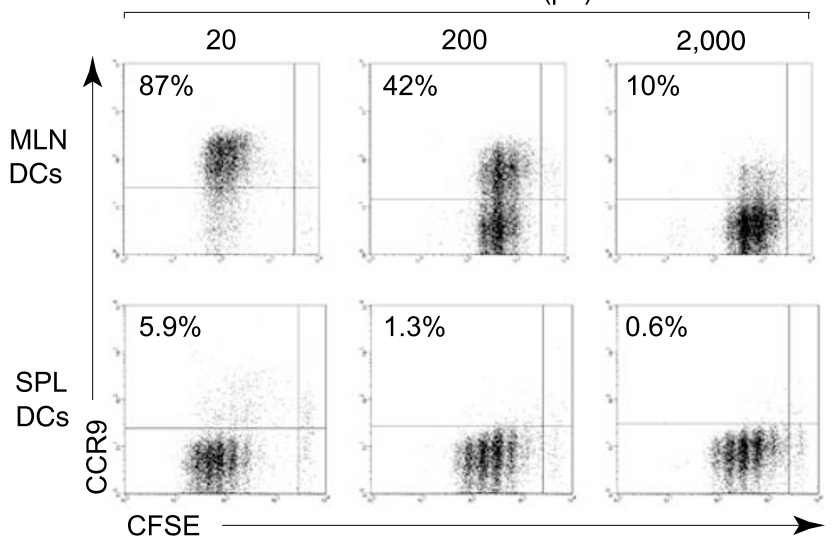

b

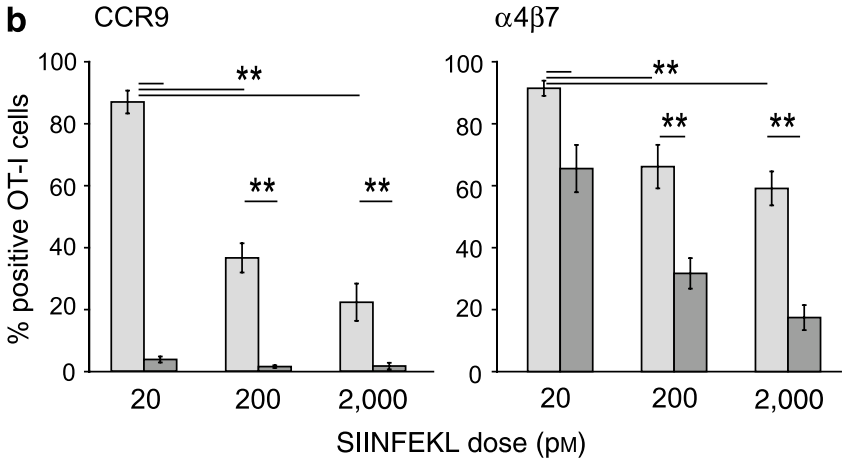

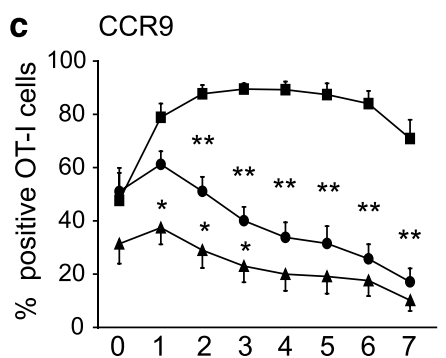

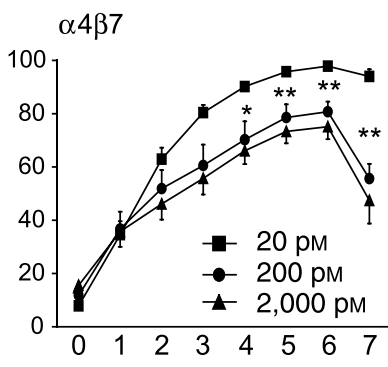

Number of cell divisions

d
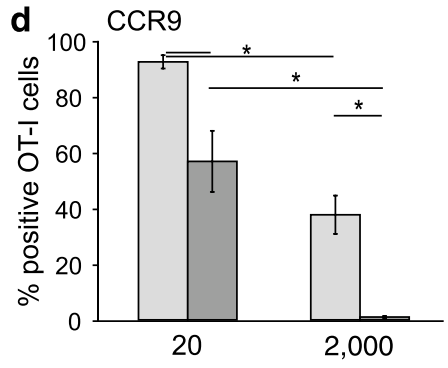

40 E-selectin ligand

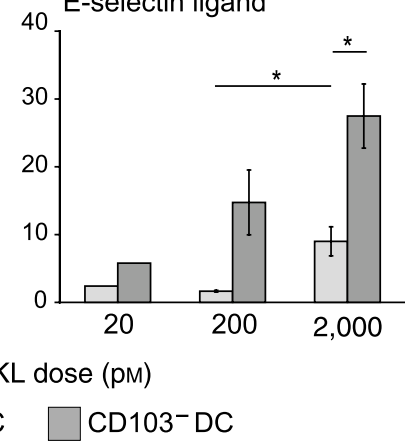

MLN DC $\square$ SPLDC

Figure 3 Induction of CCR9, $\alpha 4 \beta 7$, and E-selectin ligand expression in vitro is antigen dose dependent. (a-c) Purified CD11c ${ }^{+}$MLN or splenic DCs $\left(10^{5}\right)$ were pulsed with pOVA and incubated with $2 \times 10^{5}$ CFSE-labeled OT-I cells. After 4 days of culture, OT-I cells were analyzed for expression of (a-c) CCR9 and (b and c) $\alpha 4 \beta 7$ by flow cytometry. (b) Bars represent mean \pm s.e.m. of the percentage positive OT-I cells $(n=6) .{ }^{\star \star} P<0.01$. (c) OT-I cells were analyzed for CCR 9 and $\alpha 4 \beta 7$ expression as a function of division. Mean \pm s.e.m. from six experiments. ${ }^{*} P<0.05$, ${ }^{*} P<0.01$; asterisks are placed between compared groups. (d) Induction of CCR9 and E-selectin ligand expression by $\mathrm{CD}_{103^{+}}$and CD103- MLN DCs is antigen dose dependent. Purified $\mathrm{CD}_{103}{ }^{+}$and CD $103^{-} \mathrm{CD} 11 \mathrm{c}^{+}$MLN DCs $\left(10^{5}\right)$ were pulsed with pOVA and incubated with $2 \times 10^{5} \mathrm{CFSE}$-labeled OT-I cells. OT-I cells were analyzed for CCR9 and E-selectin ligand expression after 4 and 6 days of culture, respectively. Bars represent mean $\pm s$.e.m. of the percentage positive OT-I cells $(n=3-7) .{ }^{*} P<0.05$. CCR, CC chemokine receptor; DC, dendritic cell; MLN, mesenteric lymph node; pOVA, ovalbumin peptide; SPL, splenic.

high $\left(\mathrm{CD} 45.2^{+}\right)$antigen dose-pulsed MLN DCs were coinjected into CD $45.1^{+}$recipient mice, and their ability to localize to the spleen, MLN, and small intestinal epithelium was assessed $24 \mathrm{~h}$ later (Figure 5d,e). Although OT-I cells from both groups entered spleen and MLN with a similar efficiency, OT-I cells primed by low antigen dose-pulsed DCs had a fourfold higher capacity to localize to the small intestinal epithelium compared to OT-I cells primed by high antigen dose-pulsed DCs (Figure 5d,e). Collectively, these results demonstrate a role for antigen dose in regulating gut homing receptor induction on $\mathrm{CD}^{+} \mathrm{T}$ cells that may impact on their ability to localize to the small intestinal mucosa.

\section{DISCUSSION}

Recent studies have demonstrated a central role for intestinal LN DCs in the generation of CCR9 ${ }^{+} \alpha 4 \beta 7^{+}$"gut tropic" T cells and suggested that their capacity to induce gut homing receptors on responding $\mathrm{T}$ cells lies in a selective ability to generate RA from vitamin A (for review see refs. 27, 28). Moreover, we have recently demonstrated that only a subset of MLN DCs, expressing the integrin $\mathrm{CD} 103$, are efficient at inducing gut homing receptors on responding T cells in vitro. ${ }^{8}$ Here, using a novel RARE reporter mouse, we demonstrate that both splenic and MLN DCs are capable of enhancing RAR signaling in $\mathrm{CD} 8^{+}$ $\mathrm{T}$ cells and that the unique ability of $\mathrm{CD} 103^{+}$MLN DCs to induce gut homing receptors lies, at least in part, in their selective ability to induce RAR signaling events early after T-cell priming. We further demonstrate that DC-mediated induction of gut homing receptors is inhibited at high antigen dose without affecting RAR signaling events and that this results in less efficient T-cell localization to the small intestine. Together, these results highlight a central and competing role for DC subset-induced RAR signaling and antigen dose-dependent inhibitory signals in regulating gut homing receptor expression on $\mathrm{CD} 8{ }^{+} \mathrm{T}$ cells.

The selective ability of MLN and PP DCs to generate gut tropic effector $\mathrm{T}$ cells has been proposed to lie in their unique ability to generate RA from vitamin A. ${ }^{12}$ Consistent with this observation, we found that an RAR antagonist blocked the 
a
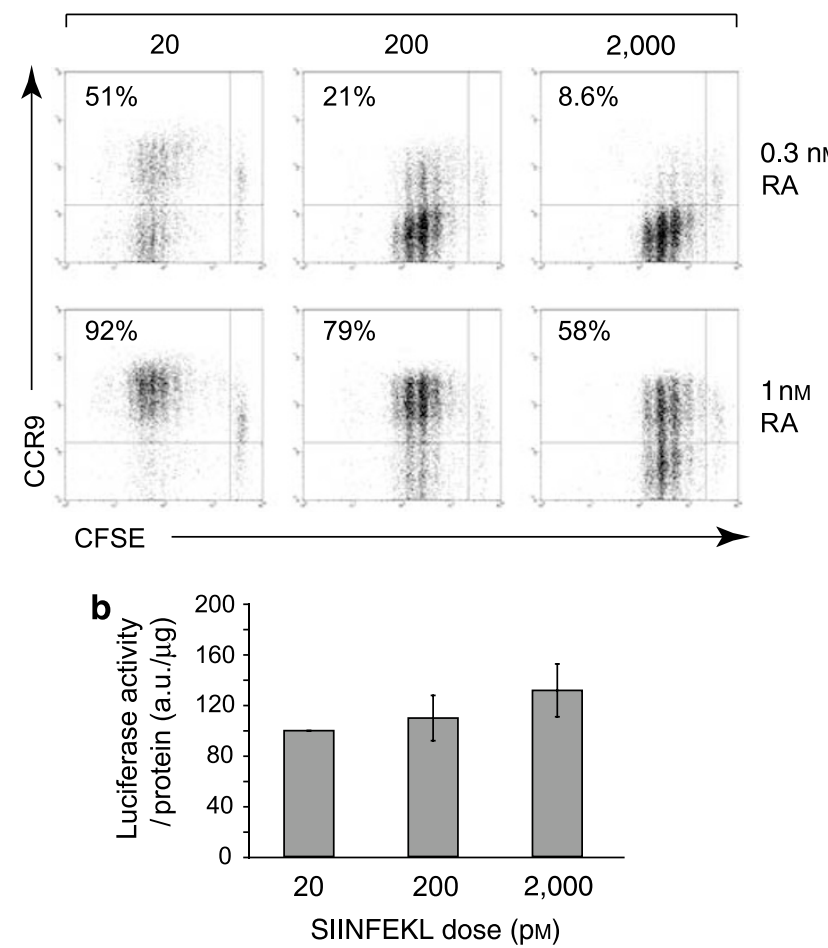

Figure 4 High antigen dose inhibition of RAR-mediated CCR9 expression does not affect RAR signaling events. (a) CD11 ${ }^{+}$splenic DCs $\left(10^{5}\right)$ were pulsed with pOVA and incubated with $2 \times 10^{5}$ CFSE-labeled OT-I cells in the presence of indicated concentrations of RA. After 4 days of culture, OT-I cells were analyzed for CCR9 expression. Numbers are percentage of CCR9 ${ }^{+}$-responding OT-I cells. Results are from one representative experiment of four to five performed. (b) RAR signaling activity does not decrease with increasing antigen dose. $A$ total of $2 \times 10^{5} \mathrm{CD} 8^{+}$DR5. OT-I cells were activated by $10^{5} \mathrm{MLN}$ DCs pulsed with various doses of pOVA, and luciferase activity was measured after $24 \mathrm{~h}$. Data are normalized to the luciferase activity in cells stimulated by MLN DCs pulsed with $20 \mathrm{pM}$ pOVA and have been normalized for variation in protein content. Bars represent mean \pm s.e.m. from four to six culture wells from two to three experiments. Freshly isolated unstimulated DR5.OT-I cells $\left(5 \times 10^{5}\right)$ show $<10$ luciferase (a.u.) per $5 \mu$ g protein. CCR, CC chemokine receptor; DC, dendritic cell; MLN, mesenteric lymph node; pOVA, ovalbumin peptide; $R A$, retinoic acid; RAR, retinoic acid receptor.

ability of MLN DCs to induce gut homing receptors on responding $\mathrm{CD}^{+}{ }^{+} \mathrm{T}$ cells. However, several key findings in this study suggest an additional level of complexity in DC-mediated RAR signaling. Firstly, we found that splenic DC-mediated induction of $\alpha 4 \beta 7$ is also RAR dependent and that splenic DCs induced similar RAR signals as MLN DCs in responding $\mathrm{T}$ cells $72 \mathrm{~h}$ after T-cell activation in vitro. Thus, splenic DCs appear to possess the enzymatic machinery to generate functional RAR ligands at concentrations sufficiently high to induce $\alpha 4 \beta 7$ expression in vitro. These findings may help explain previous observation that antigen-pulsed splenic DCs are capable of inducing $\alpha 4 \beta 7$ on T cells in vitro, particularly late after activation. ${ }^{19}$ DR5.OT-I $\mathrm{T}$ cells also received RAR-dependent signals following their activation in the spleen in vivo, suggesting that the ability of splenic $\mathrm{DC}$ to enhance RAR signaling in responding $\mathrm{T}$ cells is not due to the in vitro culture conditions used. However, in contrast to the in vitro situation, $\mathrm{CD}^{+} \mathrm{T}$ cells activated in the splenic environment fail to express $\alpha 4 \beta 7$. Thus, additional mediators within the splenic environment appear to suppress $\alpha 4 \beta 7$ induction. Alternatively, in contrast to the in vitro system, where cumulative RAR signaling may occur, $T$ cells activated in the splenic environment may not be exposed to sufficient levels of RAR ligands to induce this receptor. Secondly, we demonstrate that $\mathrm{CD}_{103^{+}}$but not $\mathrm{CD} 103^{-}$ MLN DCs are capable of inducing an early RAR signal in responding $\mathrm{CD}^{+} \mathrm{T}$ cells, and this correlated with their selective ability to drive efficient CCR9 expression in vitro. Importantly, CD8 ${ }^{+} \mathrm{T}$ cells displayed enhanced RAR signaling following their activation in the MLN compared with the spleen, demonstrating for the first time inductive site-dependent differences in RAR signaling levels in T cells in vivo. Although these results strongly suggest that RAR ligand generation by $\mathrm{CD}_{103}{ }^{+}$MLN DC underlies the selective generation of CCR $9^{+} \alpha 4 \beta 7^{+}$"gut tropic" T cells in intestinal LN, it will be important in future studies to determine the potential role of non-DC-derived RAR ligands in this process.

Although the mechanisms underlying the selective ability of $\mathrm{CD} 103^{+}$MLN DCs to induce an early RAR signal remain to be determined, we have recently demonstrated that $\mathrm{CD} 103^{+}$ DCs are present in large numbers in the small intestinal LP and that small intestinal LP DCs are particularly potent at inducing CCR9 on responding T cells in vitro. ${ }^{8}$ Furthermore, although $\mathrm{CD}_{103^{+}}$DCs are also found in the murine colon and lung, these DC populations fail to efficiently induce CCR9 expression on responding OT-I cells (Jaensson, E., Hansson-Uronen H. \& Agole, W. Manuscript in preparation). Thus, a possible explanation underlying the ability of $\mathrm{CD}_{103}{ }^{+}$MLN DCs to induce early RAR signaling in $\mathrm{T}$ cells is that these cells are imprinted with an enhanced ability to metabolize vitamin A in vivo, selectively in the small intestinal environment. The signals that regulate the ability of murine DCs to metabolize vitamin A are currently unclear; however, Szatmari et al. ${ }^{29}$ recently reported that peroxisome proliferator-activated receptor- $\gamma$ ligands play a central role in regulating retinoid metabolism in human monocyte-derived DCs by inducing retinal dehydrogenase expression. As natural peroxisome proliferator-activated receptor- $\gamma$ ligands are present in the intestinal mucosa, ${ }^{30}$ further studies examining the role of peroxisome proliferator-activated receptor $-\gamma$ signaling in imprinting $\mathrm{CD} 103^{+} \mathrm{LP}$ DCs with the ability to generate gut tropic effector $\mathrm{T}$ cells and the ability of non-small intestinal $\mathrm{CD} 103^{+} \mathrm{DC}$ populations to induce RAR signaling in $\mathrm{T}$ cells are clearly warranted.

An additional key finding of this study is the importance of antigen dose in regulating tissue homing receptor expression on $\mathrm{CD}^{+} \mathrm{T}$ cells. Activation of OT-I cells by MLN DCs pulsed with a low antigen dose, or administration of a low antigen dose in vivo, led to efficient generation of CCR9 ${ }^{+} \alpha 4 \beta 7^{+}$OT-I cells, whereas pulsing of MLN DCs or in vivo administration of a high antigen dose resulted in reduced CCR 9 and $\alpha 4 \beta 7$ levels. The ability of $\mathrm{CD} 103^{+}$and $\mathrm{CD}_{103}{ }^{-}$MLN DCs to induce gut homing receptors on responding $\mathrm{T}$ cells was also reduced at high antigen dose. Although the molecular mechanisms underlying antigen dose-dependent regulation of tissue homing receptors are currently unclear, high antigen dose appeared 
a OVA (mg)
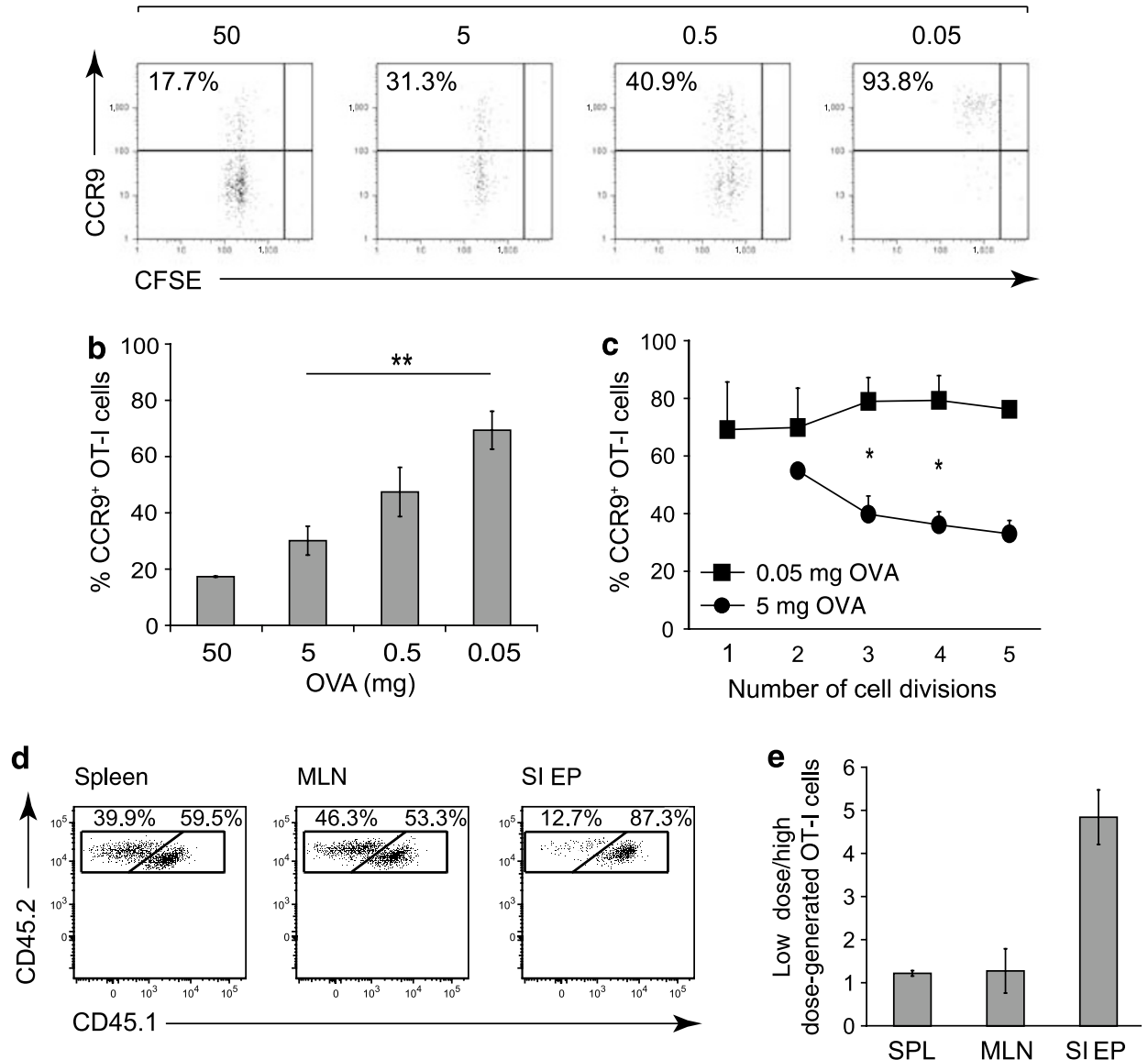

Figure 5 CCR9 induction in vivo is antigen dose dependent. (a-c) OT-I cells $\left(3-5 \times 10^{6}\right)$ were labeled with CFSE and transferred IV into C57BL/6CD45.1 recipient mice, and OVA was administered IP at the doses indicated. Mice were killed 2 or 3 days later, and CCR9 expression was determined by flow cytometry. (a) Numbers represent the percentage of CCR ${ }^{+}$cells among responding OT-I cells. (b) Bars represent the mean \pm s.e.m. of the percentage CCR9 ${ }^{+}$OT-I cells $(n=2-6) .{ }^{\star \star} P<0.01$. (c) CCR9 expression as a function of cell division. Bars represent mean \pm s.e.m. of the percentage CCR9 ${ }^{+}$OT-I cells after indicated number of cell divisions $(n=2-4) .{ }^{*} P<0.05$. (d and $\left.\mathbf{e}\right)$ OT-I cells primed by a high antigen dose have reduced capacity to localize to the small intestinal epithelium. OT-I cells were primed in vitro with low or high antigen dose-pulsed MLN DCs and after 7 days mixed at an equal ratio and injected IV into C57BL/6-CD45.1 recipient mice. The ratio of low dose-primed OT-I cells $\left(\mathrm{CD} 45.1^{+}\right.$CD $\left.45.2^{+}\right)$and high dose-primed OT-I cells (CD45.1-CD45.2 ${ }^{+}$) was assessed in the spleen, MLN, and small intestinal epithelium after $24 \mathrm{~h}$ by flow cytometry. (d) Representative flow cytometry analysis of transferred OT-I cells in the spleen, MLN, and small intestinal epithelium after gating on donor cells. (e) Bars represent mean \pm s.d. of the ratio of low-dose/high-dose-generated cells after normalization to the input ratio $(n=3)$. CCR, CC chemokine receptor; DC, dendritic cell; IP, intraperitoneally; IV, intravenously; MLN, mesenteric lymph node; OVA, ovalbumin; SIEP, small intestinal epithelium; SPL, spleen.

to antagonize the effects of RA without affecting RAR signaling in T cells. Thus, high antigen dose-dependent inhibition of CCR9 and $\alpha 4 \beta 7$ appears to act independently or downstream of RAR signaling. Sigmundsdottir et al. ${ }^{31}$ recently demonstrated that DCs can metabolize vitamin D and that the vitamin $\mathrm{D}$ metabolite $1,25(\mathrm{OH})_{2} \mathrm{D}_{3}$ can inhibit RA-induced expression of CCR9 and $\alpha 4 \beta 7$ on human anti-CD3 antibody-stimulated $\mathrm{T}$ cells. However, in apparent contrast to the situation reported with human T cells, $1,25(\mathrm{OH})_{2} \mathrm{D}_{3}$ failed to inhibit RA- or MLN DC-induced expression of CCR9 or $\alpha 4 \beta 7$ in murine $\mathrm{CD} 8^{+} \mathrm{T}$ cells, across a wide range of doses and in the presence or absence of IL-12 (Svensson, M., \& Agala W. Unpublished data). Thus, $1,25(\mathrm{OH})_{2} \mathrm{D}_{3}$ appears not to be the inhibitor of CCR9 and $\alpha 4 \beta 7$ induction in these cultures. Remarkably, expression of E-selectin ligand, which is required for effector T-cell entry into extra-intestinal sites of inflammation, ${ }^{32,33}$ increased on MLN DC-primed T cells with increasing antigen dose and thus displayed an inverse correlation to that of gut homing receptors. This implies that antigen dose may be an important parameter in regulating the generation of additional tissue tropic T-cell subsets. The antigen dosedependent increase in E-selectin ligand expression may also be of potential relevance regarding the mechanism of high antigen dose-mediated inhibition of gut homing receptors. Antigenpulsed Langerhans cells or peripheral lymph node DCs induce E-selectin ligand expression on responding $\mathrm{T}$ cells, ${ }^{19,34}$ and supernatants from peripheral lymph node DC:T-cell cultures promote induction of E-selectin ligand expression on anti-CD3 antibody-stimulated $\mathrm{T}$ cells while suppressing expression of $\alpha 4 \beta 7$ and CCR9. ${ }^{19}$ Thus, it seems possible that similar signals are 
generated in DC:T-cell cultures pulsed with high antigen dose to suppress CCR9 while enhancing E-selectin ligand expression. Indeed, our preliminary studies indicate that soluble factor(s) are in part responsible for the inhibition of gut homing receptor expression at high antigen dose, although the nature of these inhibitors remains to be resolved. As RA inhibits E- and P-selectin ligand expression on responding $\mathrm{T}$ cells, ${ }^{12}$ these data collectively suggest a model in which competing signals generated during DC: $\mathrm{T}$-cell interactions play a central role in regulating tissue homing receptor expression on responding $\mathrm{T}$ cells, and that the relative intensity of these signals is dependent on the DC source and antigen dose.

In addition to its role in gut homing receptor induction, RA was recently reported to synergize with transforming growth factor- $\beta$ to promote Treg generation ${ }^{35-39}$ and to antagonize IL-6-dependent Th17 cell development. ${ }^{37,38}$ In addition, MLN or small intestinal LP DCs, ${ }^{36,37,39}$ and in particular CD103 ${ }^{+}$ intestinal DCs, ${ }^{36,39}$ displayed an enhanced capacity to generate Treg cells, compared with splenic DCs, that was dependent on RAR signaling. Thus, DC-mediated RAR signaling appears to promote Treg and suppress Th17 development. This dual role for RAR signaling in inducing gut homing receptor expression and in promoting Treg generation is likely of importance in directing newly generated Treg populations to the small intestinal LP to help maintain gut homeostasis. Nevertheless, these observations beg the question of how effector/inflammatory gut tropic $\mathrm{CD}_{4}^{+}$ $\mathrm{T}$ cells are generated in the MLN, and the role DC-mediated RAR signaling pathways play in this process. In this regard, we have previously demonstrated that coadministration of adjuvant with antigen (IP) enhances gut homing receptor induction on MLN-primed $\mathrm{CD} 8{ }^{+} \mathrm{T}$ cells, indicating that these receptors are efficiently induced on T cells during immunogenic responses. ${ }^{8}$ Further studies aimed at unraveling the pathways regulating RAR-dependent Treg generation vs. RAR-dependent gut homing receptor induction on effector T-cell populations, including the role of adjuvant and antigen dose, will be needed to address this important issue.

In summary, results from this study demonstrate that DCmediated induction of gut homing receptors on $\mathrm{CD} 8^{+} \mathrm{T}$ cells is dependent on the ability of distinct DC populations to induce RAR signaling in responding T cells and that $\mathrm{CD}_{103}{ }^{+} \mathrm{MLN}$ DCs are unique in generating an early RAR signal that appears to underlie their selective capacity to induce CCR9. Moreover, we demonstrate a previously unrecognized role for antigen dose, functioning independently or downstream of RAR signaling, in regulating tissue homing receptor expression. Together, these results have potential important implications for the design of vaccine strategies aimed at enhancing tissue-specific immune responses.

\section{METHODS}

Mice. OT-I, C57BL/6, and C57BL/6-CD45.1 mice were obtained from Jackson Laboratory (Bar Harbor, ME). The generation and characterization of the transgenic DR5-luciferase reporter mice will be published elsewhere (K. Ebihara and R. Blomhoff, unpublished data). Briefly, the DR5 transgene contained three copies of the RARE motif from the RAR$\beta 2$ promoter (i.e., $3 \times$ DR5 elements) coupled to a luciferase reporter gene. DR5-luciferase mice that had been backcrossed to C57BL/6 mice for at least 10 generations were used for experiments. DR5.OT-I double transgenic mice were generated by crossing homozygous OT-I and DR5-luciferase mice. All mice were bred and maintained at the BioMedical Center Animal Facility, Lund University, Sweden, and all animal procedures were approved by the local ethical board.

Reagents. R10 culture media contained the following reagents (all from Gibco-BRL, Paisley, UK): L-glutamine-supplemented RPMI, 10\% fetal calf serum, HEPES (4-(2-hydroxyethyl)-1-piperazineethanesulfonic acid) $(10 \mathrm{mM})$, sodium pyruvate $(1 \mathrm{mM}), \beta$-mercaptoethanol $(50 \mu \mathrm{M})$, penicillin $\left(100 \mathrm{Uml}^{-1}\right)$, streptomycin $\left(100 \mu \mathrm{gml}^{-1}\right)$, and gentamicin $\left(20 \mu \mathrm{gml}^{-1}\right)$. DNase I and collagenase type IV, lipopolysaccharide (Escherichia coli serotype 055:B5), RA and OVA (grade VI) were from Sigma-Aldrich (Steinheim, Germany). Recombinant IL-7 and IL-15 were from R\&D Systems Europe (Abingdon, UK). Endotoxin was removed from OVA preparations using Detoxi-Gel chromatography (Pierce Biotechnology, Rockford, IL). CFSE was from Invitrogen (Paisley, UK). Synthetic pOVAs $\left(\mathrm{OVA}_{257-264}\right.$ peptide (SIINFEKL)) were from Innovagen (Lund, Sweden). The pan-RAR inhibitor AGN194310 was kindly provided by Rosh Chandraratna at Allergan (Irvine, CA).

Cell purifications and CFSE labeling. CD8 $\beta^{+}$cells and splenic or MLN DCs were isolated by MACS as previously described. ${ }^{3,6}$ CFSE labeling was performed as previously described. ${ }^{3}$ For isolation of $\mathrm{CD} 103^{+}$and CD103- MLN DCs, CD11 $\mathrm{c}^{+}$MLN DCs were enriched as described. ${ }^{6}$ DCs were then labeled with APC-conjugated anti-CD11c (eBioscience, San Diego, CA) and phycoerythrin-conjugated anti-CD103 (BD Biosciences Europe, Erembodegem, Belgium) and sorted on a FACSAria (BD Biosciences). For the experiments presented in Figure 2d, DCs were isolated from mice injected with Flt3L-secreting B16 melanoma cells, as previously described. ${ }^{8}$

In vitro cell cultures. Purified DCs were pulsed with varying concentrations of pOVA for $1 \mathrm{~h}$ at $37^{\circ} \mathrm{C}$. Following repeated washes, pOVAloaded DCs were added together with OT-I cells into flat-bottomed 96-well plates (Nunc, Roskilde, Denmark) or 24-well $0.4 \mu \mathrm{m}$ transwell plates (Costar, New York, NY). For 96-well plates and upper insert chambers of transwells, $10^{5}$ DCs and $2 \times 10^{5}$ OT-I cells were added in 200 and $100 \mu \mathrm{l}$ R10 media, respectively, whereas $2.5 \times 10^{5} \mathrm{DCs}$ and $5 \times 10^{5} \mathrm{OT}-\mathrm{I}$ cells were co-cultured in $1 \mathrm{ml}$ and $600 \mu \mathrm{l} \mathrm{R} 10$ media in 24-well plates and lower transwell chambers, respectively. Cultures were analyzed by flow cytometry after 4 days of incubation at $37^{\circ} \mathrm{C}$. For long-term cultures, cells were supplemented with $1 \mathrm{ml}$ fresh media containing $10 \mathrm{ng} \mathrm{ml}^{-1} \mathrm{IL}-7$ and IL- 15 on day 4 and were analyzed by flow cytometry after a total of 7 days of culture. Supernatants for retinoid measurements were collected at $18 \mathrm{~h}$ of culture in the dark to avoid light-induced RA breakdown.

Flow cytometry. The following fluorescein isothiocyanate-, phycoerythrin-, APC- or biotin-conjugated antibodies were used in flow cytometry analysis: anti-Ly5.1 (clone A20), anti-Ly5.2 (104), anti-CD8ß (53-5.8), anti- $\alpha 4 \beta 7$ (DATK32), anti-CD62L (Mel-14), anti-CD103 (M290), antiCD69 (H1.2F3), and anti-MHC-II (M5/114) from BD Biosciences. Anti-CD11c (HL3) and phycoerythrin-conjugated anti-Ly5.2 (104) were from eBioscience. CCR9 expression was detected using either a monoclonal rat anti-CCR9 antibody (7E7 (ref. 40)) kindly provided by O. Pabst or a polyclonal rabbit IgG anti-CCR9 antibody (K629 (ref. 41)). Monoclonal rat anti-CXC chemokine receptor 3 (4C4) was kindly provided by Millenium Pharmaceuticals (Cambridge, MA). Unconjugated antibodies were detected using relevant secondary reagents; biotinylated mouse anti-rat IgG2b (RG7/11.1) and biotinylated mouse anti-rat IgM (G53-238) were from BD Biosciences; biotinylated goat anti-rabbit IgG was from Jackson ImmunoResearch Laboratories (West Grove, PA). Biotinylated antibodies were detected using APC-conjugated streptavidin (BD Biosciences). Dead cells were distinguished using 7-amino-actinomycin D (Sigma-Aldrich). 
Flow cytometry was performed as previously described. ${ }^{3}$ Data acquisition was performed on a FACSCalibur or FACSAria (BD Biosciences) and analysis was performed using CellQuest (BD Biosciences) or FlowJo software (Tree Star, Ashland, OR).

Determination of retinol and retinol metabolites by HPLC-APCIMS/MS. HPLC-APCI-MS/MS analysis was performed as previously described. ${ }^{26}$

Luciferase measurements. Splenic CD8 ${ }^{+} \mathrm{T}$ cells were isolated from DR5 or DR-5.OT-I mice by MACS and cultured on anti-CD3 antibody $\left(10 \mu \mathrm{g} \mathrm{ml}^{-1}\right)$-coated 96 -well plates $\left(2 \times 10^{5}\right.$ cells per well; Nunc) or half area plates $\left(10^{5}\right.$ cells per well; Costar) in the presence of MLN or splenic DCs at a DC:T-cell ratio of 1:2. After 24 and $72 \mathrm{~h}$, cells were spun down in the plates and washed with phosphate-buffered saline, and the remaining cell pellets were lysed by addition of $40 \mu \mathrm{l}$ lysis buffer (Lysis Buffer; Promega, Madison, WI). Total protein concentration was determined using a BCA Protein Assay Kit (Pierce Biotechnology). For measurement of luciferase activity, $25 \mu \mathrm{l}$ of lysate was transferred to white luminometer 96-well plates (Costar) together with $40 \mu$ l luciferase assay reagent (Promega). Chemiluminescence was quantified using a Lumistar Galaxy Luminometer (Labvision, Runcorn, UK).

For assessment of luciferase activity in $\mathrm{CD}^{+}{ }^{+} \mathrm{T}$ cells from DR5.OTI mice activated in vivo, MACS-purified CD8 ${ }^{+}$cells were added to 96-well plates and assayed as described above.

Adoptive transfers. CFSE-labeled OT-I cells (CD45.2 $2^{+}, 3-5 \times 10^{6}$ per mouse) were injected intravenously (IV) into C57BL/6-CD45.1 recipient mice. One day later, mice were immunized IP with $200 \mu \mathrm{l}$ phosphate-buffered saline containing endotoxin-free OVA, with or without $50 \mu \mathrm{g}$ lipopolysaccharide. Recipient mice were killed after 2-3 days, and donor OT-I cells in the MLN were analyzed by flow cytometry.

For in vivo homing studies of in vitro-primed OT-I cells, OT-I cells were primed with MLN DCs pulsed with a high $(2,000 \mathrm{pM})$ or low ( $40 \mathrm{pM})$ antigen dose as described above. Following 4 and 6 days of culture, cells were expanded with fresh R10 culture media supplemented with IL-7 (10 $\left.\mathrm{ng} \mathrm{ml}^{-1}\right)$ and IL-15 $\left(10 \mathrm{ng} \mathrm{ml}^{-1}\right)$. After 7 days of culture, equal numbers of cells from both groups were mixed and injected in $200 \mu \mathrm{l}$ phosphate-buffered saline IV into three C57BL/6-CD45.1 recipient mice ( $4 \times 10^{6}$ total cells per mouse). After $24 \mathrm{~h}$, recipient mice were killed and the ratio of low antigen dose-primed OT-I to high antigen dose-primed OT-I cells was assessed in the spleen, MLN, and small intestinal epithelium by flow cytometry.

Statistical analysis. All statistical analyses were performed using a two-tailed Mann-Whitney test.

SUPPLEMENTARY MATERIAL is linked to the online version of the paper at http://www.nature.com/mi

\section{ACKNOWLEDGMENTS}

We thank O. Pabst (Hannover Medical School, Germany) for kindly providing the monoclonal anti-CCR9 antibody, M.-A. Wurbel and B. Mallissen (INSERM, France) for providing CCR9-/- mice, Cgene (Cgene AS, Oslo, Norway) for providing the DR5-luciferase mice, and Thomas Gundersen and Nasser Bastani (University of Oslo) for performing the retinoid analysis. We also thank Professor A. Mowat (University of Glasgow, UK) for his valuable comments during the preparation of this manuscript and Ann-Charlotte Selberg for valuable technical assistance. This work was supported by grants from the Swedish Medical Research Council, the Crafoordska, Österlund, Åke Wiberg, Nanna Svartz and Kocks Foundations, the Royal Physiographic Society, The Wellcome Trust, and the Swedish foundation for Strategic Research INGVAR II program.

\section{DISCLOSURE}

The authors declare no conflict of interest.

() 2008 Society for Mucosal Immunology

\section{REFERENCES}

1. Briskin, M.D., Winsor-Hines, A., Shyjan, N., Cochran, S., Bloom, J., Wilson, L.M. et al. Human mucosal addressin cell adhesion molecule- 1 is preferentially expressed in intestinal tract and associated lymphoid tissue. Am. J. Pathol. 151, 97-110 (1997).

2. Kunkel, E.J., Campbell, J.J., Haraldsen, G., Pan, J., Boisvert, J., Roberts, A.I. et al. Lymphocyte CC chemokine receptor 9 and epithelial thymusexpressed chemokine (TECK) expression distinguish the small intestinal immune compartment: epithelial expression of tissue-specific chemokines as an organizing principle in regional immunity. J. Exp. Med. 192, 761-768 (2000).

3. Svensson, M., Marsal, J., Ericsson, A., Carramolino, L., Broden, T., Marquez, G. et al. CCL25 mediates the localization of recently activated CD8alphabeta(+) lymphocytes to the small-intestinal mucosa. J. Clin. Invest. 110, 1113-1121 (2002).

4. Zabel, B.A., Agace, W.W., Campbell, J.J., Heath, H.M., Parent, D., Robert, A.I. et al. Human G protein-coupled receptor GPR-9-6/CC chemokine receptor 9 is selectively expressed on intestinal homing $T$ lymphocytes, mucosal lymphocytes, and thymocytes and is required for thymus-expressed chemokine-mediated chemotaxis. J. Exp. Med. 190, 1241-1256 (1999).

5. Wurbel, M.A., Philippe, J.M., Nguyen, C., Victorero, G., Freeman, T., Wooding, P. et al. The chemokine TECK is expressed by thymic and intestinal epithelial cells and attracts double- and single-positive thymocytes expressing the TECK receptor CCR9. Eur. J. Immunol. 30, 262-271 (2000).

6. Johansson-Lindbom, B., Svensson, M., Wurbel, M.A., Malissen, B. Marquez, G. \& Agace, W. Selective generation of gut tropic T cells in gut-associated lymphoid tissue (GALT): requirement for GALT dendritic cells and adjuvant. J. Exp. Med. 198, 963-969 (2003).

7. Stenstad, H., Ericsson, A., Johansson-Lindbom, B., Svensson, M., Marsal, J., Mack, M. et al. Gut-associated lymphoid tissue-primed CD4+ $T$ cells display CCR9-dependent and -independent homing to the small intestine. Blood 107, 3447-3454 (2006).

8. Johansson-Lindbom, B., Svensson, M., Pabst, O., Palmqvist, C., Marquez, G., Forster, R. et al. Functional specialization of gut CD103+ dendritic cells in the regulation of tissue-selective T cell homing. J. Exp. Med. 202, 1063-1073 (2005).

9. Mora, J.R., Bono, M.R., Manjunath, N., Weninger, W., Cavanagh, L.L., Rosemblatt, M. et al. Selective imprinting of gut-homing T cells by Peyer's patch dendritic cells. Nature 424, 88-93 (2003).

10. Stagg, A.J., Kamm, M.A. \& Knight, S.C. Intestinal dendritic cells increase T cell expression of alpha4beta7 integrin. Eur. J. Immunol. 32, 1445-1454 (2002).

11. Campbell, D.J. \& Butcher, E.C. Rapid acquisition of tissue-specific homing phenotypes by CD4(+) T cells activated in cutaneous or mucosal lymphoid tissues. J. Exp. Med. 195, 135-141 (2002).

12. Iwata, M., Hirakiyama, A., Eshima, Y., Kagechika, H., Kato, C., Song, S.Y. et al. Retinoic acid imprints gut-homing specificity on T cells. Immunity 21, 527-538 (2004).

13. Mora, J.R., Iwata, M., Eksteen, B., Song, S.Y., Junt, T., Senman, B. et al. Generation of gut-homing IgA-secreting $B$ cells by intestinal dendritic cells. Science 314, 1157-1160 (2006).

14. Blomhoff, R. \& Blomhoff, H.K. Overview of retinoid metabolism and function. J. Neurobiol. 66, 606-630 (2006).

15. Duester, G. Families of retinoid dehydrogenases regulating vitamin $A$ function: production of visual pigment and retinoic acid. Eur. J. Biochem. 267, 4315-4324 (2000).

16. Kastner, P., Mark, M. \& Chambon, P. Nonsteroid nuclear receptors: what are genetic studies telling us about their role in real life? Cell 83, 859-869 (1995).

17. Balmer, J.E. \& Blomhoff, R. Gene expression regulation by retinoic acid. J. Lipid Res. 43, 1773-1808 (2002).

18. Bastien, J. \& Rochette-Egly, C. Nuclear retinoid receptors and the transcription of retinoid-target genes. Gene 328, 1-16 (2004). 
19. Dudda, J.C., Lembo, A., Bachtanian, E., Huehn, J., Siewert, C., Hamann, A. et al. Dendritic cells govern induction and reprogramming of polarized tissue-selective homing receptor patterns of T cells: important roles for soluble factors and tissue microenvironments. Eur. J. Immunol. 35, 1056-1065 (2005).

20. Lanzavecchia, A. \& Sallusto, F. Progressive differentiation and selection of the fittest in the immune response. Nat. Rev. 2, 982-987 (2002).

21. Valitutti, S., Muller, S., Dessing, M. \& Lanzavecchia, A. Different responses are elicited in cytotoxic T lymphocytes by different levels of T cell receptor occupancy. J. Exp. Med. 183, 1917-1921 (1996).

22. Gett, A.V., Sallusto, F., Lanzavecchia, A. \& Geginat, J. T cell fitness determined by signal strength. Nat. Immunol. 4, 355-360 (2003).

23. Nagpal, S. \& Chandraratna, R.A. Recent developments in receptorselective retinoids. Curr. Pharm. Des. 6, 919-931 (2000).

24. Idres, N., Marill, J., Flexor, M.A. \& Chabot, G.G. Activation of retinoic acid receptor-dependent transcription by all-trans-retinoic acid metabolites and isomers. J. Biol. Chem. 277, 31491-31498 (2002).

25. Lippman, S.M. \& Lotan, R. Advances in the development of retinoids as chemopreventive agents. J. Nutr. 130, 479S-482S (2000).

26. Gundersen, T.E., Bastani, N.E. \& Blomhoff, R. Quantitative highthroughput determination of endogenous retinoids in human plasma using triple-stage liquid chromatography/tandem mass spectrometry. Rapid Commun. Mass Spectrom. 21, 1176-1186 (2007).

27. Agace, W.W. Tissue-tropic effector T cells: generation and targeting opportunities. Nat. Rev. 6, 682-692 (2006).

28. Mora, J.R. \& von Andrian, U.H. T-cell homing specificity and plasticity: new concepts and future challenges. Trends Immunol. 27, 235-243 (2006).

29. Szatmari, I., Pap, A., Ruhl, R., Ma, J.X., Illarionov, P.A., Besra, G.S. et al. PPARgamma controls CD1d expression by turning on retinoic acid synthesis in developing human dendritic cells. J. Exp. Med. 203, 2351-2362 (2006)

30. Dubuquoy, L., Rousseaux, C., Thuru, X., Peyrin-Biroulet, L., Romano, O. Chavatte, P. et al. PPARgamma as a new therapeutic target in inflammatory bowel diseases. Gut 55, 1341-1349 (2006).

31. Sigmundsdottir, H., Pan, J., Debes, G.F., Alt, C., Habtezion, A., Soler, D. et al. DCs metabolize sunlight-induced vitamin D3 to "program" T cell attraction to the epidermal chemokine CCL27. Nat. Immunol. 8, 285-293 (2007).

32. Austrup, F., Vestweber, D., Borges, E., Lohning, M., Brauer, R., Herz, U et al. $\mathrm{P}$ - and E-selectin mediate recruitment of T-helper-1 but not T-helper-2 cells into inflamed tissues. Nature 385, 81-83 (1997).

33. Tietz, W., Allemand, Y., Borges, E., von Laer, D., Hallmann, R., Vestweber, D. et al. CD4+ T cells migrate into inflamed skin only if they express ligands for E- and P-selectin. J. Immunol. 161, 963-970 (1998).

34. Dudda, J.C., Simon, J.C. \& Martin, S. Dendritic cell immunization route determines CD8+ T cell trafficking to inflamed skin: role for tissue microenvironment and dendritic cells in establishment of T cell-homing subsets. J. Immunol. 172, 857-863 (2004)

35. Benson, M.J., Pino-Lagos, K., Rosemblatt, M. \& Noelle, R.J. All-trans retinoic acid mediates enhanced $T$ reg cell growth, differentiation, and gut homing in the face of high levels of co-stimulation. J. Exp. Med. 204, 1765-1774 (2007)

36. Coombes, J.L., Siddiqui, K.R., Arancibia-Carcamo, C.V., Hall, J., Sun, C.M., Belkaid, Y. et al. A functionally specialized population of mucosal CD103+ DCs induces Foxp3+ regulatory T cells via a TGF- $\beta$ and retinoic acid dependent mechanism. J. Exp. Med. 204, 1757-1764 (2007).

37. Mucida, D., Park, Y., Kim, G., Turovskaya, O., Scott, I., Kronenberg, M. et al. Reciprocal TH17 and regulatory T cell differentiation mediated by retinoic acid. Science 317, 256-260 (2007).

38. Shambach, F., Schupp, M., Lazar, M.A. \& Reiner, S. Activation of retinoic acid receptor- $\alpha$ favours regulatory $T$ cell induction at the expense of IL-17-secreting T helper cell differentiation. Eur. J. Immunol. 37 (2007).

39. Sun, C.M., Hall, J.A., Blank, R.B., Bouladoux, N., Oukka, M., Mora, J.R. et al. Small intestine lamina propria dendritic cells promote de novo generation of Foxp3T reg cells via retinoic acid. J. Exp. Med. 204, 1775-1785 (2007)

40. Pabst, O., Ohl, L., Wendland, M., Wurbel, M.A., Kremmer, E., Malissen, B. et al. Chemokine receptor CCR9 contributes to the localization of plasma cells to the small intestine. J. Exp. Med. 199, 411-416 (2004).

41. Carramolino, L., Zaballos, A., Kremer, L., Villares, R., Martin, P., Ardavin, C. et al. Expression of CCR9 beta-chemokine receptor is modulated in thymocyte differentiation and is selectively maintained in CD8(+) T cells from secondary lymphoid organs. Blood 97, 850-857 (2001). 